\title{
Scandal over Soviet artificial blood research project
}

\section{London}

THE darker side of the Soviet Academy of Sciences was revealed last week with a claim by Dr Genrikh Ivanitskii that a major research project was closed down improperly on the initiative of the late $\mathrm{Dr}$ Yurii Ovchinnikov, for many years head of the Institute of Bioorganic Chemistry of the Soviet Academy of Sciences. The project concerned the search for a synthetic fluid that could temporarily serve as a replacement for blood.

According to Ivanitskii, who lost his job as director of the academy's Institute of Biophysics at Pushchino in the infighting, the research was stopped because a 'legend' had grown up in the academy that no serious work in medical biology could be carried out without the participation of Ovchinnikov and his institute.

According to Ivanitskii, the research produced a product, perftoran - a perfluorocarbon, which represented a major breakthrough in medical research and hence a threat to Ovchinnikov's monopoly. Not all Soviet biologists would agree with Ivanitskii on the merits of perftoran. What is perhaps more important, however, is his suggestion that research can be closed down without a proper peer assessment by people who are neither competent to judge nor impartial.

Ivanitskii's account, in a letter to Literaturnaya Gazeta, stated that the research carried out under a directive of the praesidium of the Academy of Sciences, signed by Ovchinnikov himself, was entrusted to two academy institutes, the Institute of Biophysics and the Institute of Elemento-Organic Compounds. Three promising compounds were synthesized which, Ivanitskii said, gave the Soviet Union the lead over foreign teams working in this field. Yet from 1983 onwards, the academy's praesidium neglected to make the required annual assessment of interim results, in spite of frequent reminders from the researchers. In 1984, the research was "slowed down", and work on perftoran and other blood substitutes was omitted from the 1986-90 plan.

Furthermore, from 1982 onwards, the laboratory at the Institute of Biophysics where the perftoran research was going on became the subject of an investigation by the public prosecutor's office. The Serpukhov Town Party Bureau became highly critical of the work of the laboratory (which it was not competent to

\section{Industrialists in force}

\section{London}

INDUSTRIALISTS are a significant force on the new Universities Funding Council (UFC) which next April will replace the Universities Grants Commission (UGC) as adviser to the UK government on grants to individual universities. The government announced the composition of the council last week. Four members are from industry, one is from commerce and two have interests both in industry and in the academic world, including the chairman of the council. Of the 14 members of the council, the number with business interests is seven, compared with only four of the UGC's 18 members. Sir Peter Swinnerton-Dyer, chairman of the UGC, becomes chief executive of the new body.

In some parts of the science community, there is concern that the strength of the industrial interests on the council will result in research being too closely directed towards the needs of industry at the expense of freedom to pursue curiositydriven research. Dr John Mulvey of the University of Oxford, who is also secretary of Save British Science, says concern would be justified if criteria for supporting research were no longer primarily scientific. Otherwise, he says, the move is a sensible one which will improve industry's

\section{on new funding body} understanding of universities.

Swinnerton-Dyer says concern over the criteria for funding research is "unreasonable" and that in the transition from the

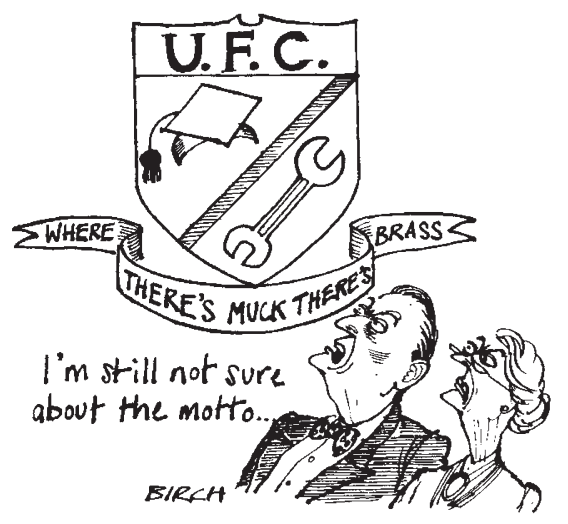

UGC to the UFC, changes "are not going to be dramatic".

The UFC is perceived as having greater powers and more direct control over universities than its predecessor under the powers granted to it by the 1988 Eduation Reform Act (see Nature 334, 371; 1988) but the government denies this is so.

Christine McGourty judge). Several members of the team left the institute or transferred to other laboratories. Finally, in December 1985, the head of the team, Dr F. Beloyartzev, committed suicide, leaving a note that he could no longer bear to live "in conditions of calumny". A "crudely tendentious" posthumous attack on him appeared in Sovetskaya Rossiya, and the investigation into his suicide was carried out, Ivanitskii alleges, in a very one-sided manner.

When a commission was eventually convened by the academy to assess and wind up the research, it was headed by Academician Yakov Kolotyrkin, a physical chemist who had, he himself states, no knowledge either of medicine nor of the working of the Institute of Biophysics. This, according to the then president of the academy Dr Anatolii Aleksandrov, would keep things impartial. In fact, in spite of his lack of inside knowledge, Kolotyrkin soon realized that the commission was not impartial. The documents submitted to it contained "a mass of unanswered questions", and a suggestion from Academician Aleksandr Fokin, director of the Institute of Elemento-Organic Compounds, that the commission should include scientists who had worked on perftoran was vetoed by Ovchinnikov.

At the same time, the question of Ivanitskii's dismissal was raised, although, when Kolotyrkin challenged Ovchinnikov, the latter admitted that there had been no complaints about Ivanitskii's work. Nevertheless, while Kolotyrkin, the chairman of the commission, was ill in hospital, the other members closed down the research and dismissed Ivanitskii.

In addition to Ivanitskii's letter and Kolotyrkin's account of the working of the commission, Literaturnaya Gazeta also published testimonials to Beloyartsev, Ivanitski and perftoran from Academician Fokin and from two doctors who had used perftoran in clinical trials. Their testimony adds up to a sharp attack on the late Dr Ovchinnikov - somewhat ironically in view of their rebukes to Sovetskaya Rossiya for attacking Beloyartsev when he was no longer alive to defend himself.

Literaturnaya Gazeta's main concern with what it calls the "banal and at the same time tragic history" of the perftoran affair is that, in spite of perestroika the danger of such incidents remains. Only recently, Literaturnaya Gazeta's commentator noted, Izvestiya reported a similar conflict between the Computer Centre at Pushchino and the Serpukhov Town Party Bureau (the same as had improperly criticized the Institute of Biophysics). The lesson of the perftoran affair, Literaturnaya Gazeta said, is that there should be some legal provisions to defend scientists and their work from arbitrary interference by administrators and bureaucrats - including academic ones.

Vera Rich 